\title{
Locomotion Methods of Pipe Climbing robots: A Review
}

\author{
P. Chattopadhyay ${ }^{1, *}$, S. Ghoshal ${ }^{2}$, A. Majumder ${ }^{2}$ and H. Dikshit ${ }^{2}$ \\ ${ }^{1}$ Central Mechanical Engineering Research Institute, Durgapur 713209, India \\ ${ }^{2}$ Department of Mechanical Engineering, Indian Institute of Technology(ISM), Dhanbad 826004, India
}

Received 9 November 2017; Accepted 20 July 2018

\begin{abstract}
Inspections of industrial pipe lines by the robots are essential as these autonomous systems are applied to explore inaccessible positions. Their intelligence and reliability ensure operators to monitor and control various part of the plant from a safe location. The complex geometry, hazardous content materials, pipe bends etc. have forced for judicious designing of the insisted robots. The improvement has grown rapidly and different types of locomotion systems have been introduced. This paper undergoes with locomotion techniques of various IN-pipe and OUT-pipe climbing robots with proper examples. A comprehensive classification of the discussed robots has been prepared based on this study.
\end{abstract}

Keywords: Climbing mechanisms, Locomotion systems, Pipe Climbing techniques, Climbing Speed, Bio-mimetic robots

\section{Introduction}

Gas/oil transmission industrial pipeline systems in nuclear, power and process plants have passed through steady maintenance as these pipes are subjected to corrosion and abrasion by the fluids or gases within the pipe. Reactions from external environments like oxidization, ageing and mechanical stress are also responsible for pipeline failure. Routine inspections are indeed essential to predict the pipe condition. Latest inclusion of probes in manual inspection units has augmented search techniques. Still inspection tools of the pipes are not fully automated and search operation has also turned into a cost incurred time-bound activity. In order to reduce the inspection time and cost, several pipe climbing robots have been proposed. Researchers all over the world are now focussing on systems which are able to navigate in the manifold. Roh [1] first proposed the general locomotion categorization strategies used to solve the in-pipe inspection problems and by following the development of pipe inspection robots, it has been classified into several forms according to the movement patterns as pig type(passively driven by the fluid pressure), wheel type, caterpillar type, wall-pressed type, walking type, inchworm type and screw type [2-7]. Pipe bends constraints are being negotiated by differential-drive steering (for single body systems) or articulated structures. Extensive developments have been in progress in recent years to make the robot move in narrow slot and complex structure. The realization of novel locomotion equipped with advanced actuator and mechanisms such as Electro-rheological valve, Electromagnetic actuator, parallel link manipulator, pantograph mechanism, pneumatic valve adds flexibility and enables the robot to move in inaccessible environment [8-12]. The design aspects and locomotion principles of climbing robots have already been discussed by several

\footnotetext{
*E-mail address: priyo.chatterjee31@gmail.com

ISSN: $1791-2377$ @ 2018 Eastern Macedonia and Thrace Institute of Technology. All rights reserved.

doi:10.25103/iestr.114.20
}

authors $[7,83]$ but this paper solely describes the locomotion systems of pipe climbing robots. Based on the studies and experimental prototypes over the last few decades, Locomotion systems are classified in four major categories: Legged type [13-17]. Tracked type [18-26], Wheeled type [27-58] and Limbless type [59-82]. Legged locomotion was the first used in development of IN-pipe type robot [17]. Wheeled locomotion are widely regarded due to ability in branch navigation and mobility and robots use such locomotion are categorized as robots having passive or active wheels. Tracked type robots are also simple in structure [23]. The belt bounding wheels exert more friction for the robot, thus making it able to move on uneven surfaces whereas Limbless type robots move without legs and primarily uses the body itself as a propulsive structure. The Locomotion strategies are briefly discussed in the succeeding sections with adequate examples and finally a classification table has been prepared where the robots are arranged chronologically.]

\section{Locomotion}

\subsection{Legged locomotion}

A very common locomotion principle in the range of climbing robots is the use of limbs or legs which are pushed against the pipe walls to support the body. A Spider-like climbing robot developed by Siemens AG as pipe and tubing inspection tool by using legged locomotion may be referred as the first invention of IN-pipe climbing robot [17]. The robot consists of eight legs with 2-DOF each. For its locomotion, the robot pushes two opposite legs against the internal surface of the pipe, in a way to get stuck, and afterward, brings the body in the movement direction (Fig. 1).

An in-pipe micro robot with piezoelectric actuator was introduced which can move inside very small curved pipe in horizontal as well as in vertical direction. The main components are stacked PZT elements, legs, inertia mass, 
gripper, controller and power supply (Fig. 2). The PZT actuator deforms slowly with the change in the electric field and drives the counter mass. When the inertia force of the counter mass goes beyond the friction force of legs, the legs slide forward keeping the counter mass stationary [13].
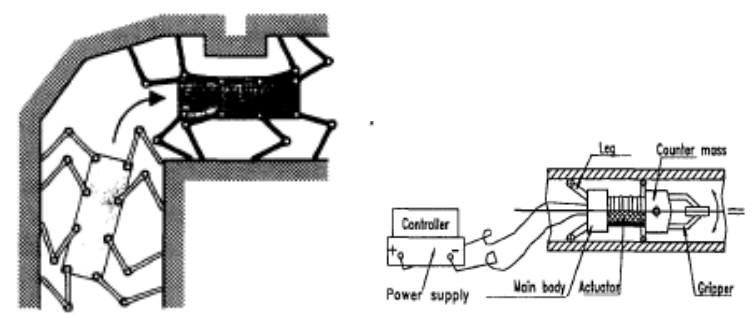

Fig. 1. A spider like octapod robot [17] Fig. 2. PZT type in-pipe robot

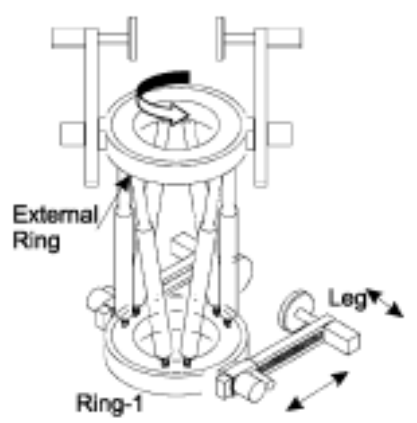

Fig. 3. G-S Platform [14]

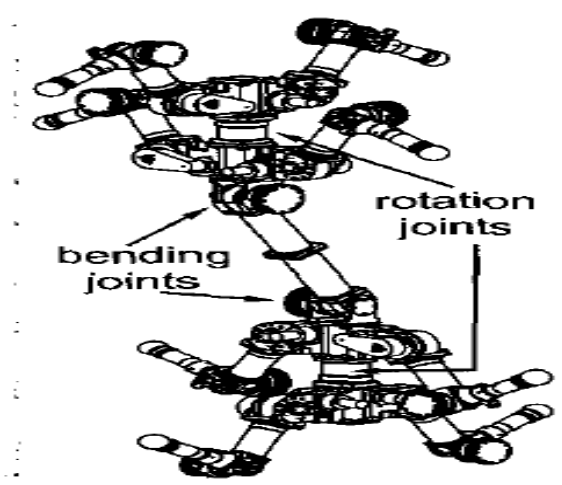

Fig. 4. Mortiz [15]

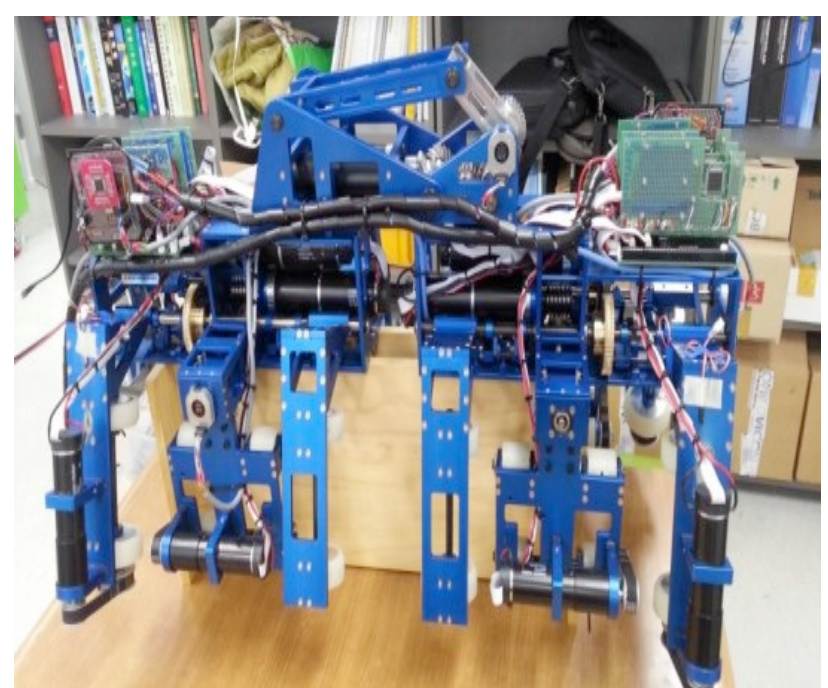

Fig. 5. Out-pipe climbing robot [16]
Gough-Stewart (G-S) platform as a climbing robot was proposed as a novel solution for carrying out tasks on tubular structures that involve a high risk for workers [14]. The G-S platform is designed as a parallel robot with two rings connected by six linear actuators. Each ring has two legs which allow the robot to attach one ring to the pipe surface while the other ring travels along the structure (Fig. 3).The "MORITZ" robot was developed by Technical University of Munich [15]. This robot consists of 8 legs (four on each body extreme) that can rotate along the longitudinal axis with the help of two rotational joints (Fig. 4). The two bending joints allow the robot to bend while negotiating in curved pipes. Another type of legged out-pipe climbing robot was presented which consists of two moving modules and a connecting arm (fig. 5). The robot can climb as well as rotate on the pipe surface and each module is provided with two degrees of freedom, allowing the robot to avoid obstacles and navigate through the flanges, fixtures and branch pipes [16]. From the study one can find pipe climbing robots with four or eight legs. It is evident that legged robots are potentially better fitted to uneven terrain and has the ability to step over obstacles easily. Conversely, the higher number of degrees of freedom leads to a complex mechanical structure and comparably lower operating speed with respect to other locomotion principles.

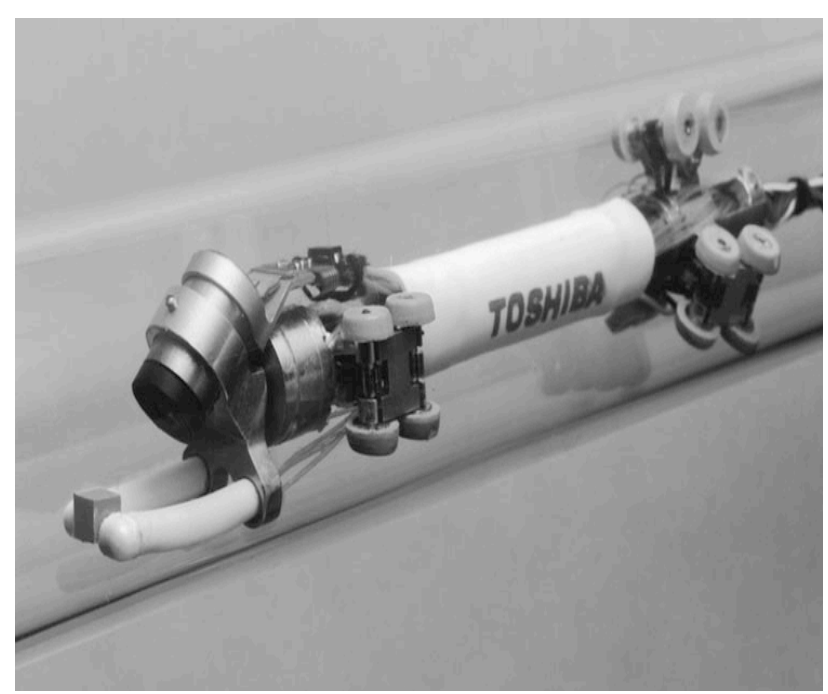

Fig 6. TOSHIBA [27]

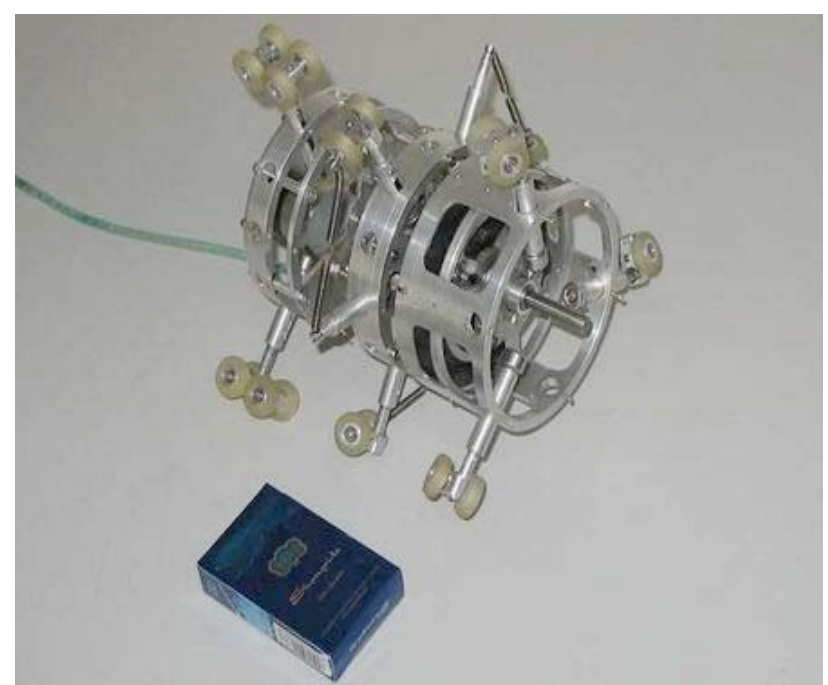

Fig. 7. An Adaptable mobile robot [33] 


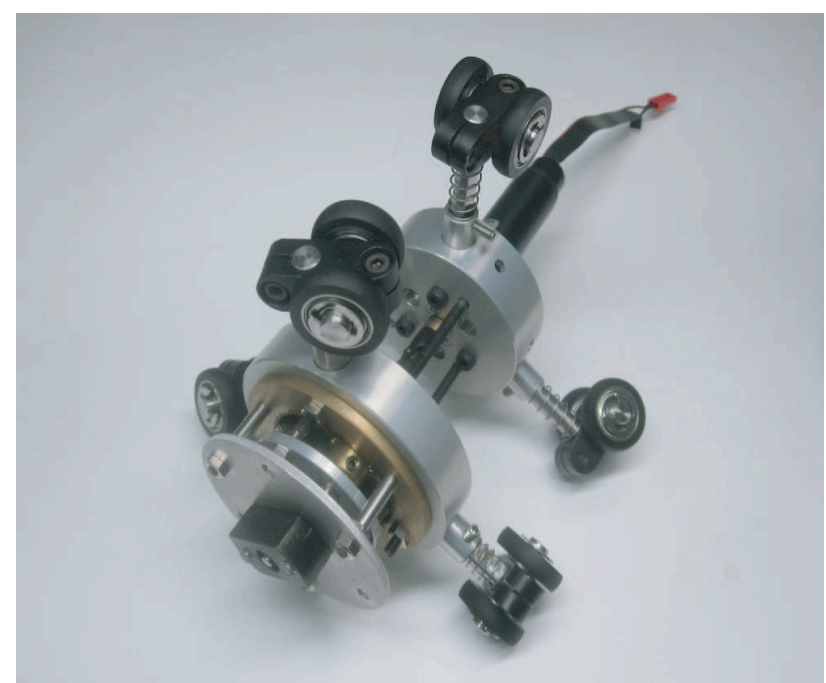

Fig. 8. Robot [37]

\subsection{Wheeled locomotion}

Wheeled locomotion has a wide range of application in the field of climbing robots. This mechanism enables a robot to move rapidly and requires less energy when compared to other types of robotic locomotion mechanisms. It can also reach a relatively high speed. Wheel type robots can be divided into directly driven wheel (active wheel) and passively driven wheel [33] .Some of the wheeled robots feature both active and passive wheels, they are categorized as hybrid wheeled type locomotion. "Toshiba" was developed as a micro pipe-inspection robot for 1-in pipelines that offers good mobility and has suitable functionality for practical use. The functional elements are a planetary wheel mechanism, a micro electromagnetic motor, a pneumatic micro actuator, a micro CCD camera, and a pneumatic wobble motor (Fig. 6). The planetary wheel mechanism drives the rear wheel of robot against the pipe inner wall by the actuation of a single motor. For the negotiation of curved pipe a flexible link is attached with planetary wheel mechanism [27]. A Screw principle micro robot was proposed by considering the advantage of climbing the stepped portion of small pipes without using any special actuator. Tires are mounted on the main body and torque is applied to the main body through a flexible wire. The tire rolls spirally around the centre axis of the body causes the micro robot to move forward [28]. Similar kind of locomotion can be observed in case of "THES-I" where rollers are free to rotate spirally around the axis of the pipe without rotating the body itself [29]. Another robot based on adaptive mobile mechanism with screw drive wheel has been shown in Fig. 7. The robot is equipped with a latter driving arm mechanism which produces enough traction force (by using a compression spring inside the driving arm) to maintain proper contact with the pipe wall [33]. All of these robots are using a single actuator for propulsion and suitable for straight vertical pipes, but as per as a curved pipe is concerned more than one actuator is needed. Fig. 8 shows a prototype of an in-pipe robot composed of two units. The front unit consists of angled passive wheels and power is transmitted from rear unit to front unit through a universal joint. Although there is only one DC motor is used for actuation, the robot exhibit decent mobility in both straight and curved pipes [37]. "Heli-pipe" is also analogous to [37] which is made up of two parts connected by a universal joint (Fig. 9). One part is directed along the pipe by a set of wheels moving parallel to the pipe axis, whereas the other part is bound to follow a helical motion [30].

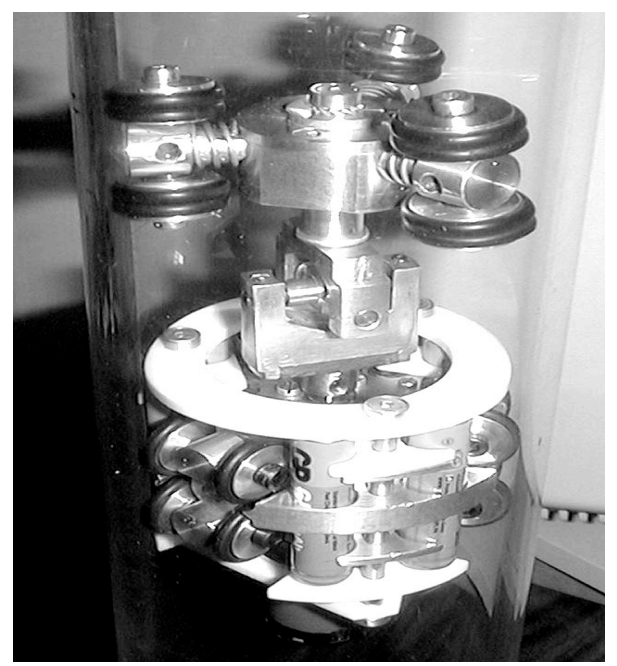

Fig. 9. Helipipe [30]

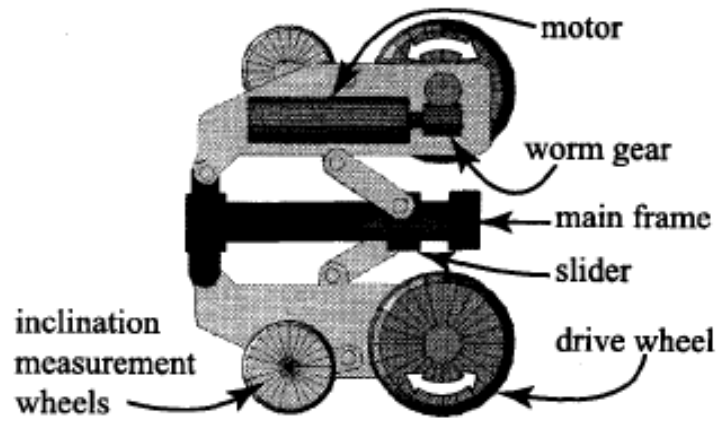

Fig. 10. THES-III

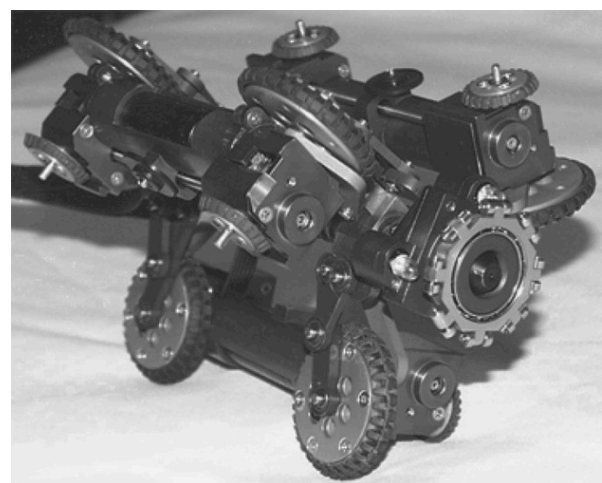

Fig. 11. MRINSPECT IV [1]

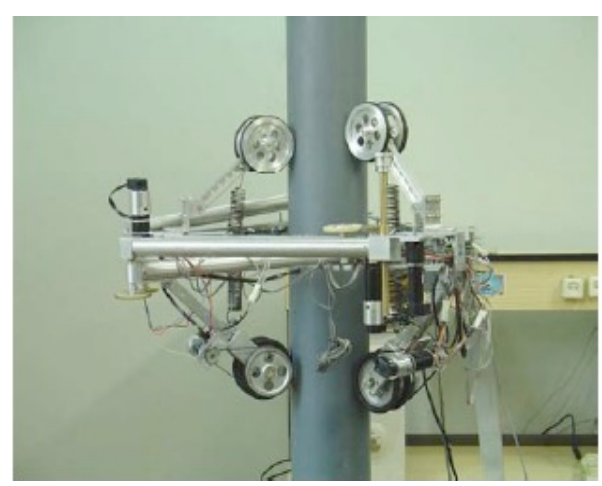

Fig. 12. UT-PCR [311] 


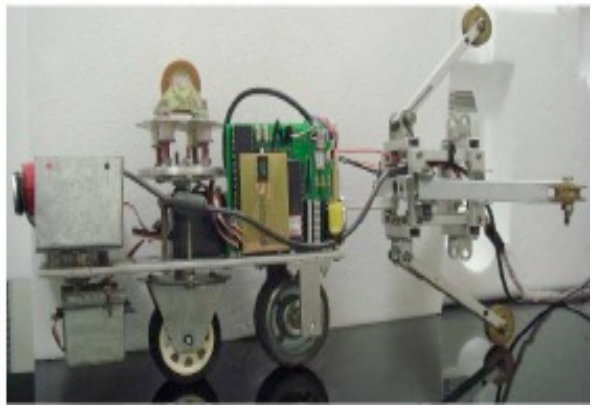

Fig. 13. NTU-Navigator [35]

Theseus Series" was developed based on the concept of "whole stem drive" which is very operational to allow an in-pipe vehicle to travel long distance in the pipeline. The drive mechanism of THES-III is poised with four links arranged equally around the body and each link has a large-sized drive wheel (Fig. 10). The driving wheels are constrained to the pipe wall by CCV (Control Configured Vehicle) mechanism [29]. MRINSPECT IV (Multifunctional Robot for IN-pipe inSPECTion), the newest of MRINSPECT had been developed for the inspection of urban gas pipelines with 4-inch inside diameter. MRINSPECT IV is configured with a link construction capable of being folded forward and backward. Three separated driving modules provide high flexibility and agility in a narrowly constrained space (Fig. 11). The steering mechanism with differential-drive wheels allows it to become accustomed to most of the existing configurations of pipelines [1]."UT-PCR" a wheel based pole climbing robot was developed by University of Teheran. It consists of a triangular body and six limbs. Wheels are attached to the tip of each limb (Fig. 12). Three lower wheels are actuated with DC motor while the upper three wheels remain passive [31]. This type of locomotion system can be considered as a hybrid wheeled locomotion due to the presence of both active and passive wheels. "NTU-Navigator", a lightweight modular pipe inspection robot was developed by National Taiwan University [35]. The driving module consists of a worm gear, a DC motor and a driving wheel. The steering module composed of a servo motor and two steering wheels. The height of the robot is self-adjustable by providing a spring linked to upper wheel (Fig. 13). Wheeled locomotion can also be found with a parallel linkage mechanism with folding characteristics. A robot consists of a main body, three wheel (active) chains, and three clutch wheel (passive) parts along with the parallel linkage mechanism is shown in Fig. 14 [39]. An another robot uses a similar mechanism but requires only two wheel chains which are arranged 180 degrees apart from each other (Fig. 15), so additional sensors can be added on both sides of the body [40].

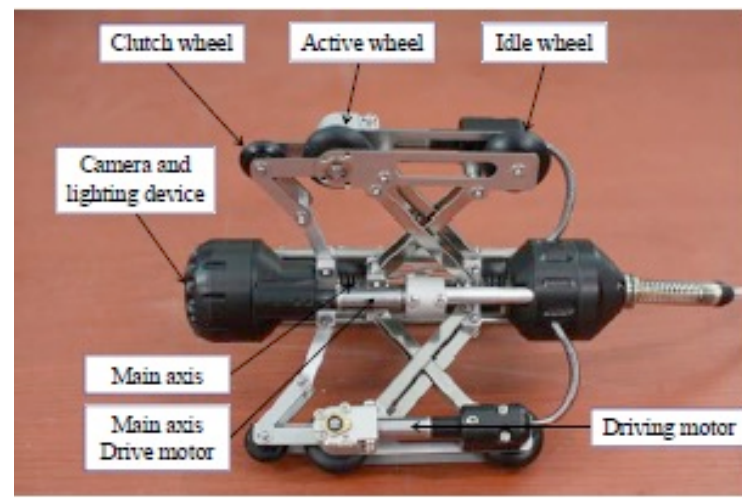

Fig. 14. Pipe line inspection robot with a mechanical clutch[39]

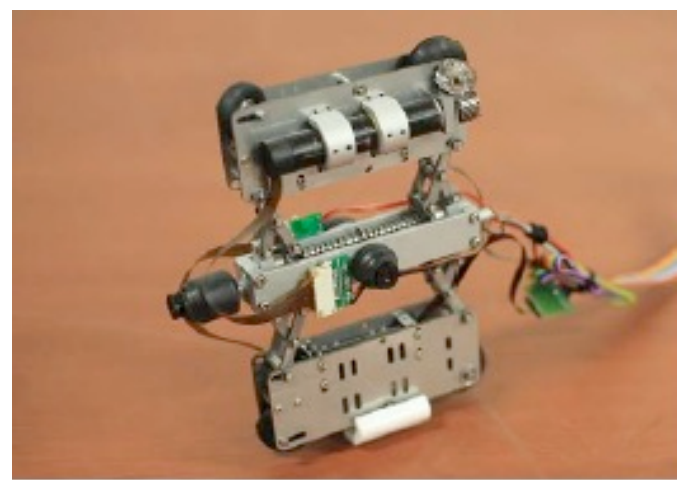

Fig. 15. Robot with two wheel chain mechanism [40]

The "PIRATE" (Pipe Inspection Robot for Autonomous Exploration) is a robot consists of four identical modules and one rotation module (Fig. 16). The robot is structured with two V-shape clamping connected by the rotation module. Every Joint is provided with a wheel having an in-wheel drive system. The flexible modular configuration produces the necessary traction force on the wheels to maintain friction and orientation within the pipe [41]. A group of researchers from the Yonsei University developed a pipe inspection robot (Fig. 17) with Adaptable Quad Arm Mechanism (AQAM) and Swivel Hand Mechanism (SHM). These two mechanism enables the robot to travel through various branch pipes with zero-radius of curvature [42].

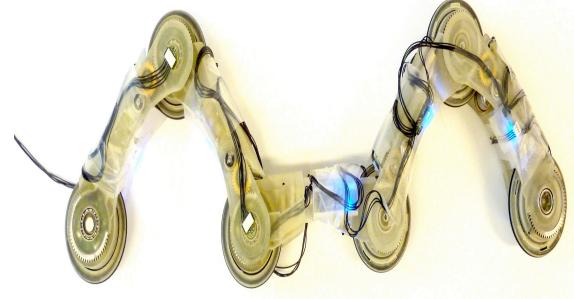

Fig. 16. PIRATE [41]

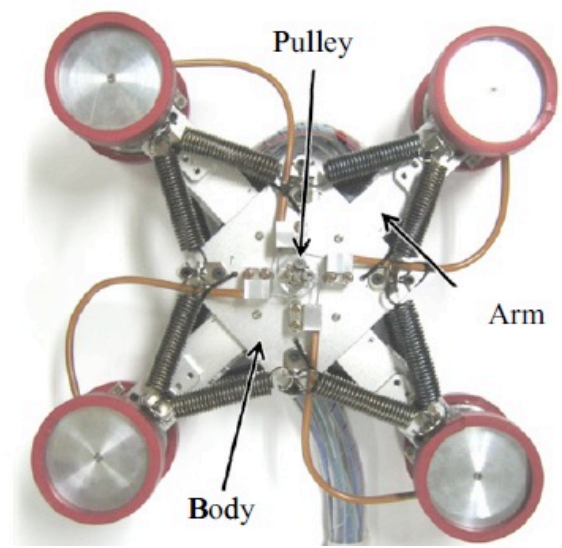

Fig. 17. Robot with AQAM and SHM [42]

All the above mentioned robots have some mechanical system to push their wheels against the pipe wall in order to generate friction force used for propulsion. Since most of the industrial pipe materials are ferromagnetic in nature, these kind of complex mechanical system can be avoided by introducing magnetic wheels. A compact robot with two magnetic wheels in bicycle arrangement is shown in Fig. 18. The robot is integrated with an active lifter-stabilizer and a steering unit [32]. Fig. 19 represents a simple magnetic wheeled robot capable of climbing in any pipeline with 
internal diameter ranging from $80 \mathrm{~mm}$ upwards. The steering mechanism of this robot is achieved by using differential drive system [43]. On a comparable note, another robot was developed [34] with additional linear actuators and slide bearings for guiding the linear movements (Fig. 20). "Tubulo" is a train-like miniature climbing robot comprises of four modules coupled with special connectors having two degrees of freedom (Fig. 21). The robot can be reconfigured by adding or removing different modules. Standard magnetic wheels are used as holding system. The robot can move in ferromagnetic tubes with $25 \mathrm{~mm}$ diameter and able to pass curves of $150 \mathrm{~mm}$ curvature [36].A flexible squirm pipe robot was proposed with magnetic wheels for inspecting the inner casing of pipes with complex shaped structures. The robot motion is realized by the flexible helical axle and the gear nut arrangement (Fig. 22). The locomotion is achieved by squirm type walk i.e. alternate contraction of the left and right body over the helical axle [38].

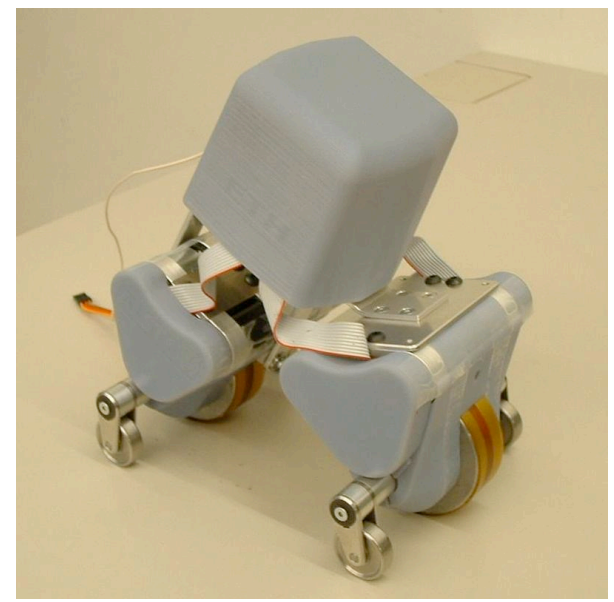

Fig. 18. Compact magnetic wheeled robot [32]

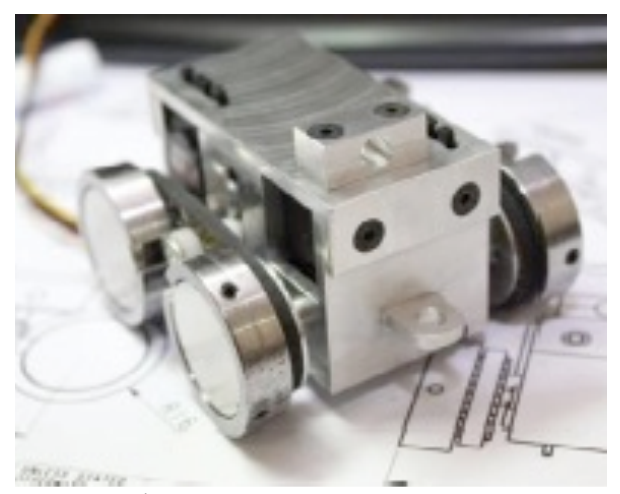

Fig. 19. Robot [43]

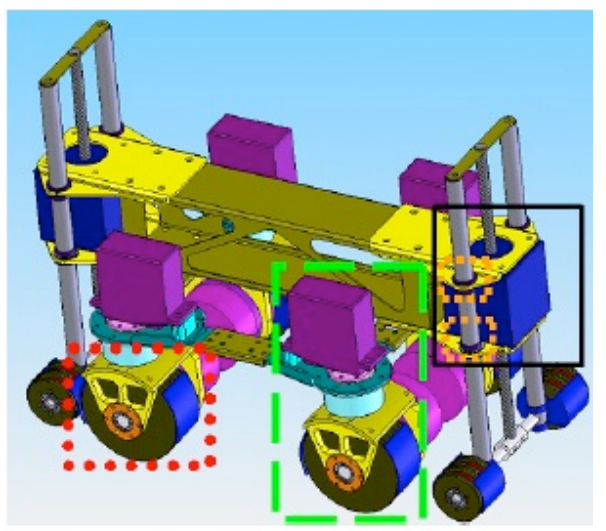

Fig. 20. Robot [34]

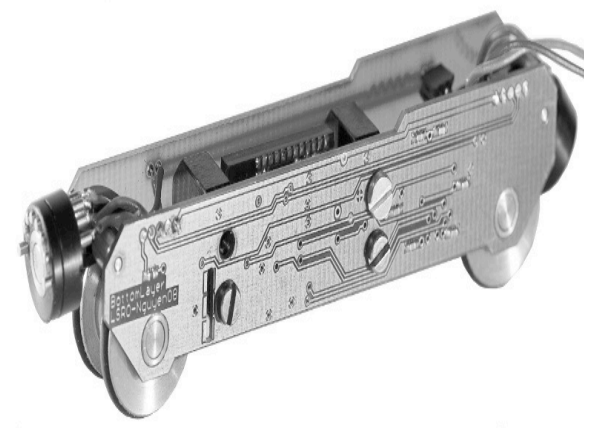

Fig. 21. TUBULO [36]

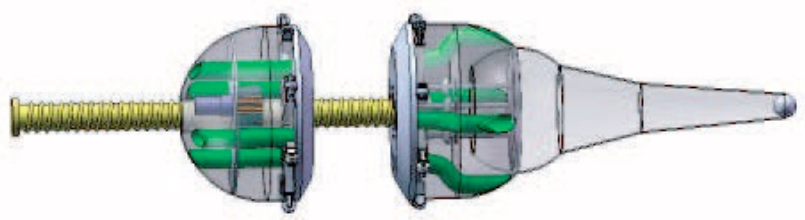

Fig. 22. Robot [38]

\subsection{Tracked locomotion}

Tracked locomotion provides more traction compared to wheeled robots and is suitable for rough surfaces. It's also capable of giving a better pay load capacity. But in terms of speed it lies in between legged and wheeled locomotion. "FAMPER" has been designed to inspect $150 \mathrm{~mm}$ pipelines and consists four caterpillar tracks operated by DC motors (Fig. 23). The robot is provided with an extendable link mechanism which enhances its mobility. The caterpillar tracks can be tilted up to $5^{\circ}$ with respect to the main body to overcome the motion singularity problem [18]. "PAROYS-II" was developed by Yonsei University. The robot comprises of three parts which includes a centre module, a track module and an active pantograph mechanism (Fig. 24). Three caterpillar tracks are connected symmetrically to the centre module through the pantograph mechanism. The robot is capable of moving through pipes with diameter ranging from $400 \mathrm{~mm}$ to $700 \mathrm{~mm}$ [19].A modular wall-pressed caterpillar robot is presented in Fig. 25. The body units are identical and consists of wheels, timing belts, pulleys and actuators. Number of modules or body units can be increased depending on the pipe diameter and they are coupled via a connecting link. Tracks are driven by DC motors and RC servo motors are used to rotate the connecting links to push body units against the pipe wall [20].

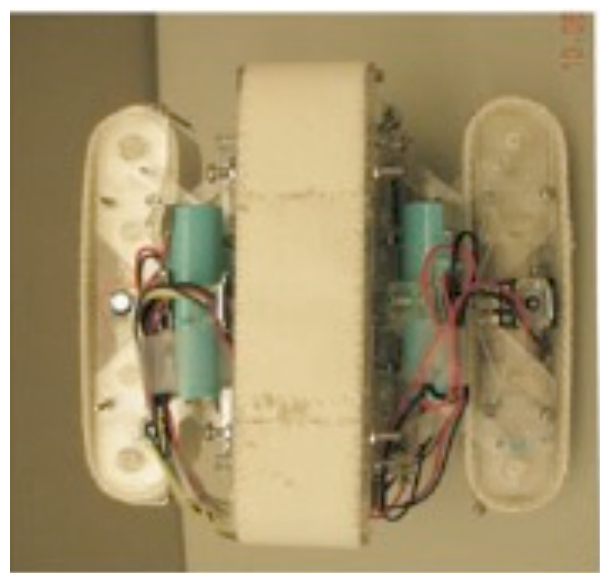

Fig. 23. FAMPER [18] 


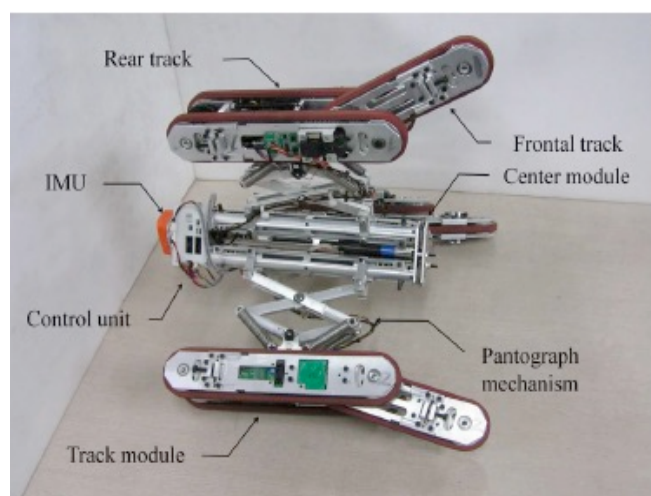

Fig. 24. PAROYS-II[19]

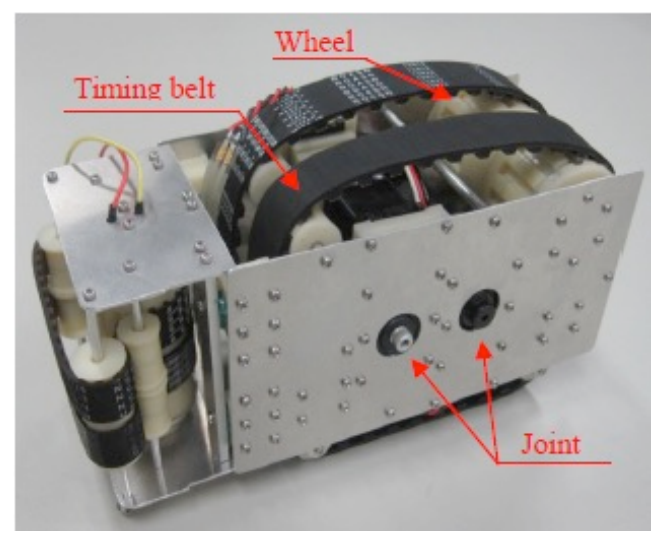

Fig. 25. Robot by [20]

"LS-01" is a simple tracked robot with foldable top platform acts as the camera holder as shown in Fig. 26, called as holder for fibre optic camera (HFOC). It was mainly built to serve the purpose of boiler header inspection. The robot uses standard differential drive system for steering [21].

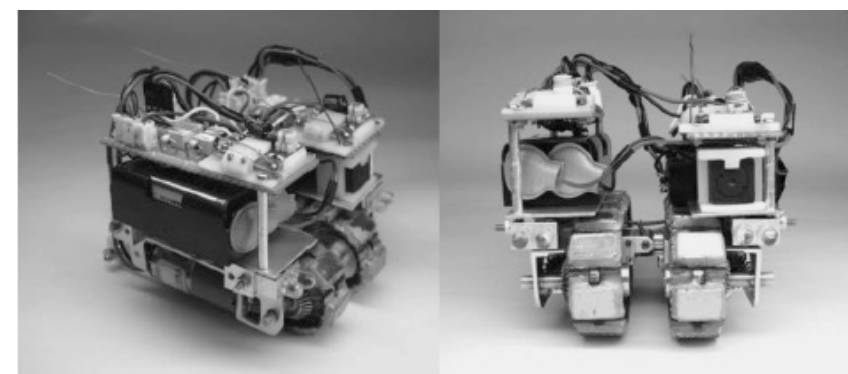

Fig.28. Robot [23]

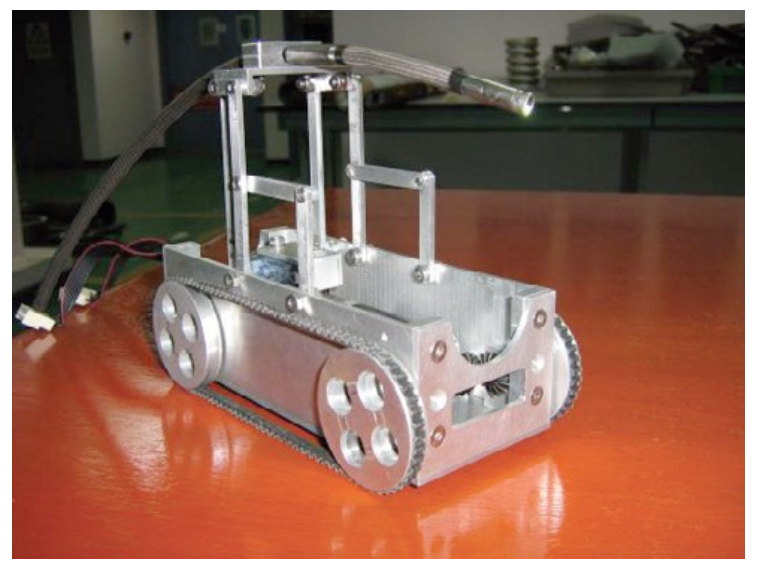

Fig. 26. LS-01 [21]

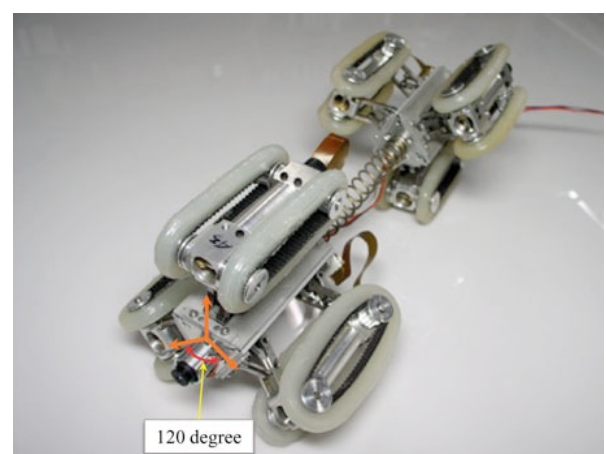

Fig. 27. Robot [22]

A crawler-type robot mechanism is adopted for the inspection of $80-100 \mathrm{~mm}$ pipelines. The robot body is assembled as a triangle as shown in Fig. 27, which is suitable to support the three linkage structure. A spring loaded four bar mechanism inflates the robot to grip the pipe wall [22].

A precisely optimized magnetic crawler type wireless inspection robot is shown in Fig. 28. Two crawlers are connected by a hinge in such a way that it can follow the curvature of the inner surface of the pipe by pitching and rolling. A small motor with a velocity reduction mechanism is employed for driving purpose and turning characteristics is achieved by controlling right and left crawler independently [23].

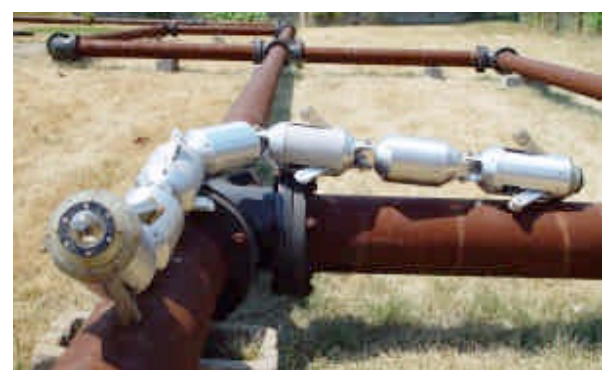

Fig. 29. Explorer [59]

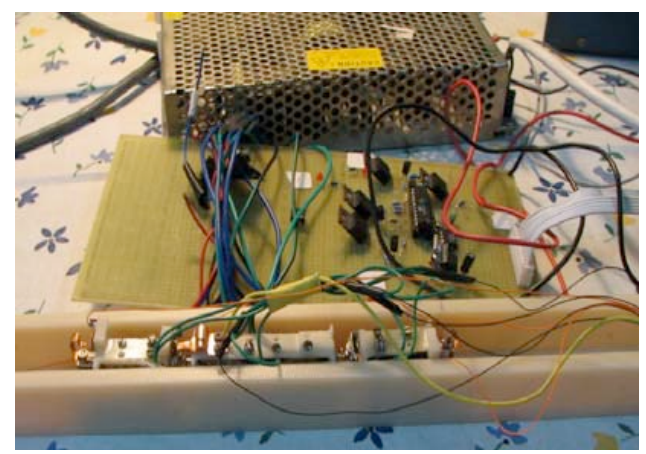

Fig. 30. Robot $[60]$

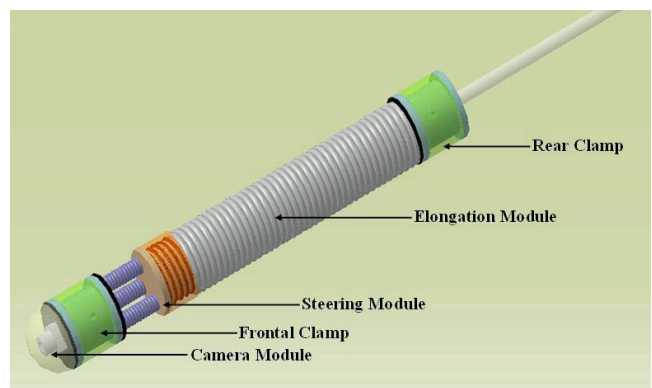

Fig. 31. Robot [61] 


\subsection{Limbless locomotion}

Instead of exploiting wheels or legs, the limbless robots utilize their body for propulsion. Most of the robots consist of identical modules and the necessary propulsive effort for locomotion is accomplished by driving the joints. Many of them are biologically inspired and follows Inchworm, Snake or Trunk-like motion, whereas some of the locomotion rely exclusively on body undulation.Carnegie Mellon University developed "Explorer", an untethered remotely controlled modular inspection robot for visual assessment in gas-mains. The robot architecture is made of seven bodies connected to each other by means of articulated joints (Fig. 29). Some of the locomotor modules connect to their neighbours with pitch-roll joints, while the others are connected via pitch-only joints. "Explorer" is capable of moving through straight pipe segments and sharp bends using the articulated steering joints [59]. A bio-mimetic pipe crawling micro-robot was developed based on self-excited vibration. The locomotion is inspired by the peristaltic insects. The robot consists of three driving units connected by two moving joints (Fig. 30). Two linear electromagnetic solenoid are used as actuators and the self-excited vibration is realized through alternative switching of electromagnetic solenoids [60]. By using only one pneumatic line, an inchworm like micro robot for pipe inspection was invented. It has an extensible body with clampers at either end of its body as shown in Fig. 31, the inchworm's locomotion is achieved by attaching the rear portion of its body to a surface of the pipeline via its clamper, and extending its body forward, followed by attaching the front portion to the surface, and taking the rear part of its body to the direction of motion [61].The crawling motion of a modular snake robot in an inclined pipe is realized by altering the shape of the robot (Fig. 32). The shape of the robot determines the direction of force that the robot applies to the wall. The robot uses the frictional force created between the robot and the inner surface of the pipe to drive the robot forward. Five different motion shape code was designed and tested on the snake robot out of which the motion shape that has the largest number of waveforms along the length of the robot offers fastest crawling speed [62]."3DCLIMBER" was developed by university of Coimbra to climb over 3D structures with bends and branches. It is able to stay attached to the structure with one gripper, and the arm can perform manipulation (Fig. 33). The climbing module consists of a 3-DOF planer serial arm and a $\mathrm{Z}$-axis rotating mechanism. Each gripper includes two unique multi-fingered $\mathrm{V}$-shaped bodies [63].Ilmenau University of Technology prepared a modular climbing robot called "RAUPI" as shown in fig. 34. The locomotion module is encompasses with a servo drive system, electronic hardware, rigid aluminium frame and each module are connected by direct or passive elements. Servo motor with a special type of gear arrangement offers $t$ torque that generates gripping force between gripping module and the substrate [64].

A minimalistic climbing robot, created at Carnegie Mellon's Bio-robotics and Manipulation lab, uses vibration for to move quickly in pipelines. A simple motor turns an unbalanced mass at a uniform velocity, which generates an oscillating acceleration and force (Fig. 35). As the mass swings around, it causes the robot to bounce back and forth between the tube walls [65]. The globular magnetic actuator group is illustrated in Fig. 36 that exhibits a very high thrust force and is capable of free reverse motion through elongation and contraction of eight shape-memory-alloy (SMA) coils in complex pipes. The propulsion module of each actuator consists of two identical permanent magnets, two acrylic pipes, a translational spring, and an electromagnet [66]. A steerable inchworm type in-pipe inspection robot was fabricated for navigation in a wide range of commercial pipes such as vertical, curved, "Y" and "T" branched pipes (Fig. 37). The robot mainly embraces of two clamper modules and one extensor module. The extensor module consists of a frame, four continuum links, pulleys, bevel gear sets, wheel and two actuators. The robot can steer in various directions by adjusting the length of the continuum links [67].

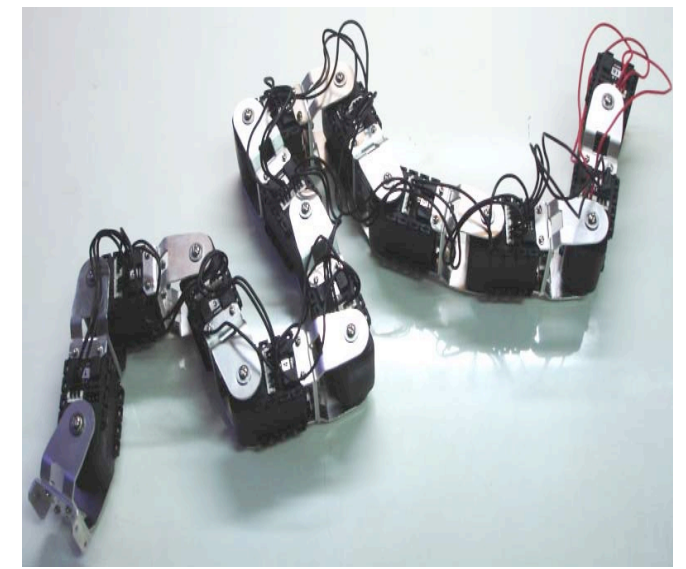

Fig. 32. Snake Robot [62]

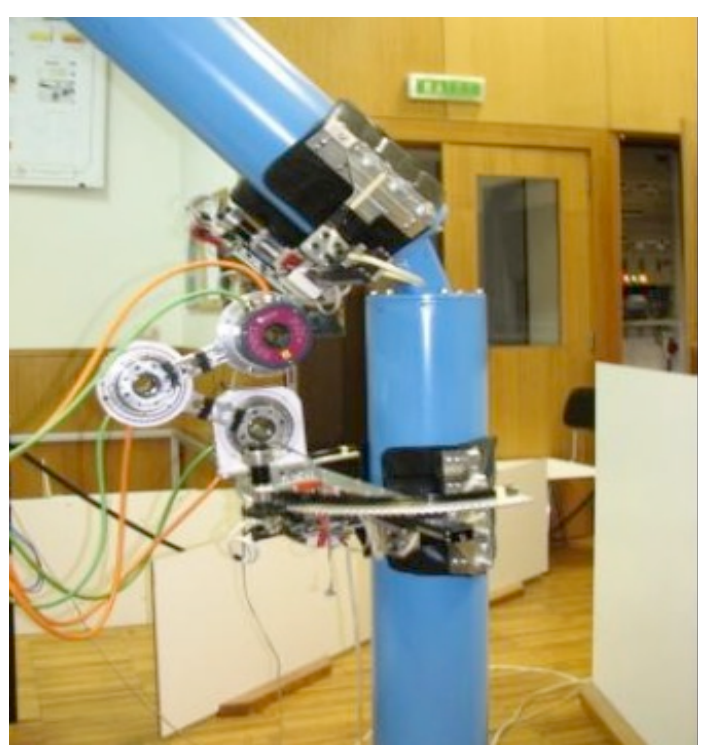

Fig. 33. Robot [23]

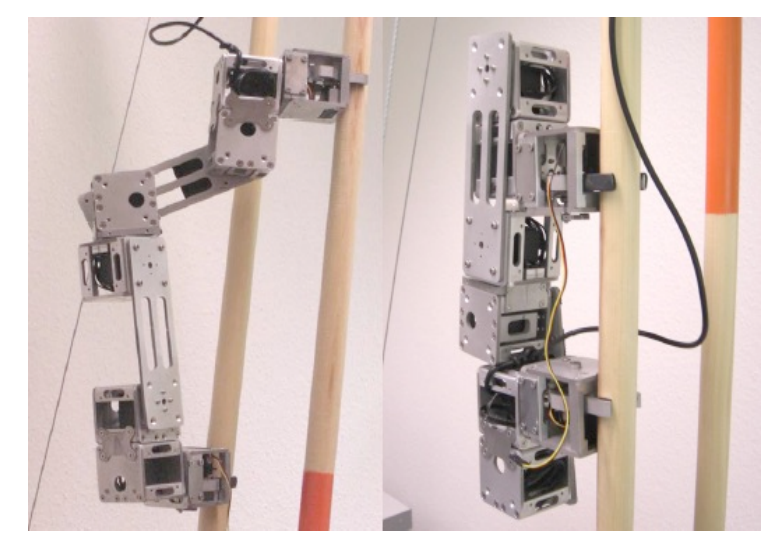

Fig. 34 RAUPI [64] 


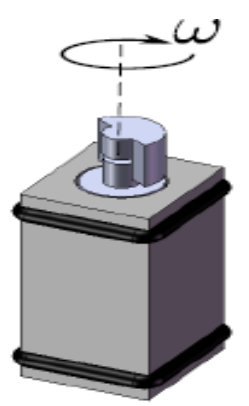

Fig. 35. Robot [65]

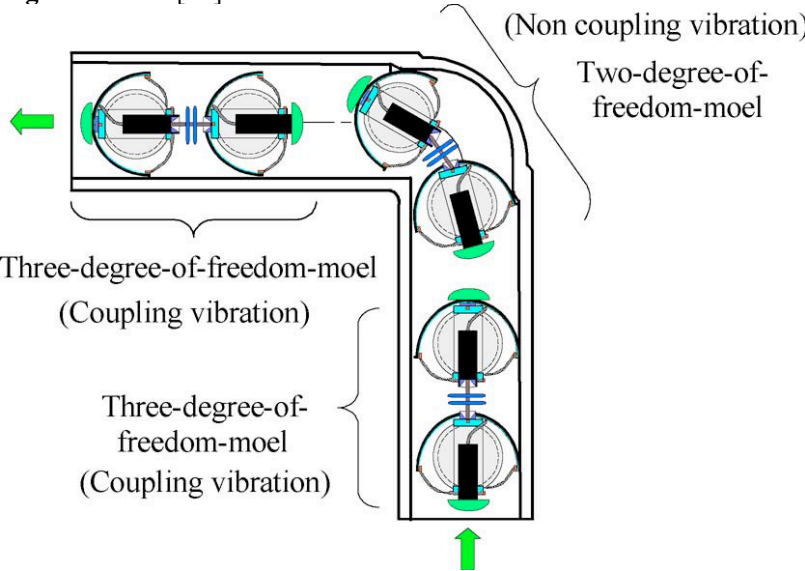

Fig. 36. Equivalent model of actuator group [66]

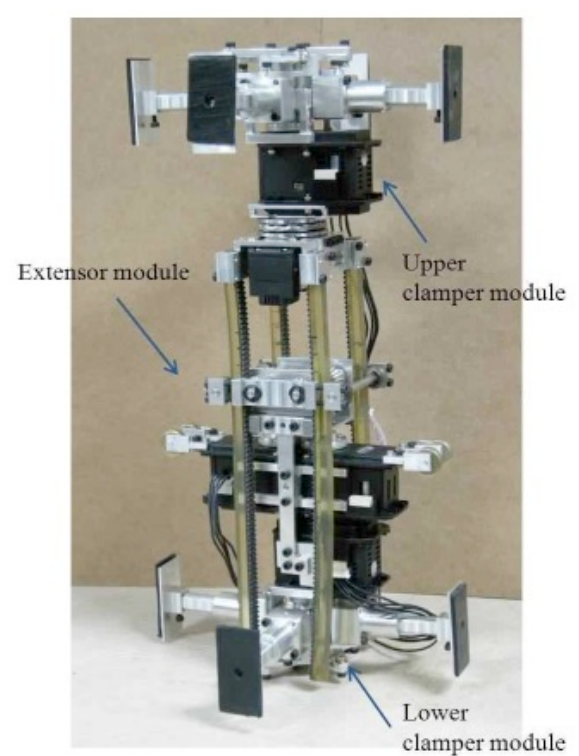

Fig. 37. Robot [67]

Atomic Energy Research Institute, Korea developed a vision based pole climbing robot to inspect the piping system in hazardous zone. The robot has 5 links and two grippers at both ends of the robot as appeared in Fig. 38 and moves along cylindrical pipes overcoming obstacles such as flanges and valves [68]. A compact external pipe crawler robot was built by Indian Institute of Science. The robot imitates an inchworm motion by following a clamp-and-push mechanism. Two SMA (Shape Memory Alloy) actuated radially deployable compliant ring actuators are used to serve the purpose (Fig. 39). The ring actuator has a compliant mechanism that transforms circumferential motion to radial motion which yields uniform grip on the pipe [69].To improve the traction ability of in-pipe robots, self-locking mechanism is introduced to work as a part of the clamp. Fig. 40 displays a robot, mainly made up of five parts in series: two clamps at two ends, one telescopic driving mechanism in the middle, and two linkages liable for connecting the cylinder with the clamps. Clamps are utilized to generate force and form cessations with pipelines. Pneumatic actuation system is used to mimic an inchworm like locomotion [70].

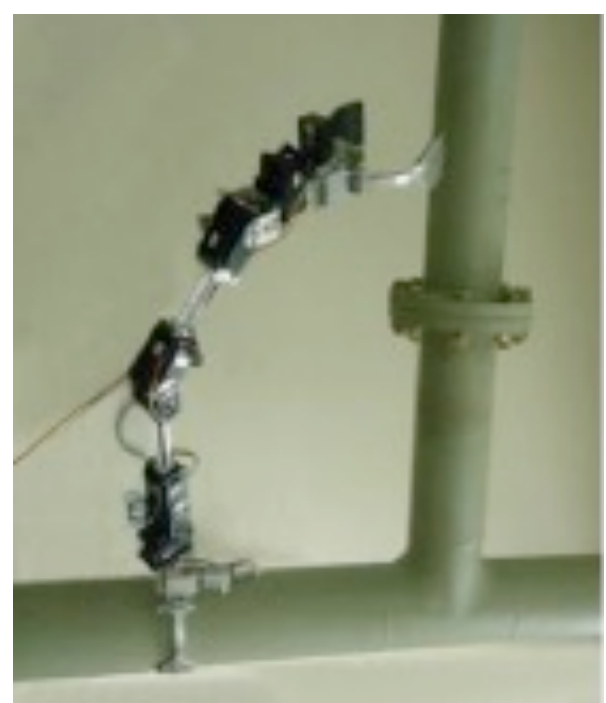

Fig. 38. Vision based pole climbing robot [68]

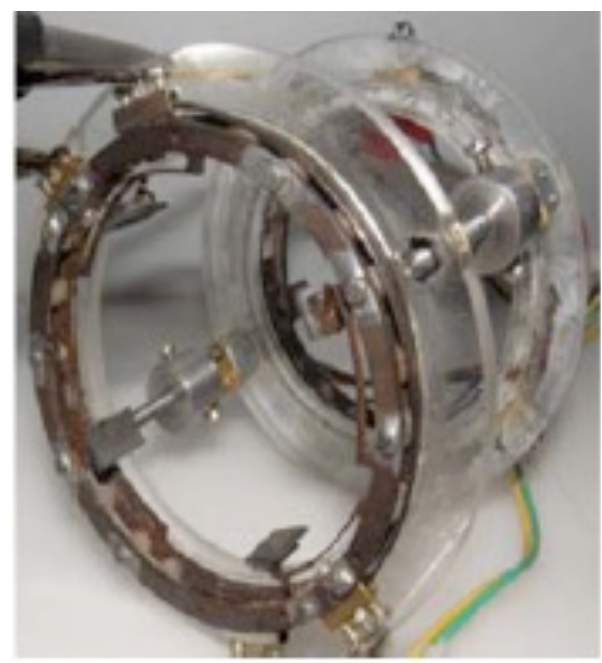

Fig. 39. Prototype of Crawling Robot [69]

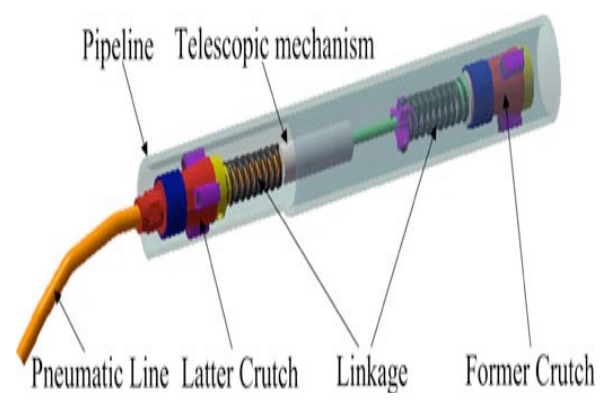

Fig. 40. Robot by [70]

\section{Application \& Discussions}

Robots are developing at a fair rate and mostly based on wheeled and tracked locomotion. Conventional methods for inspection and repairing of pipe lines in industry are highly 
complex and costly. Frequent troubles are occurred in pipe line circuits and caused by corrosion, cracking, wall thinning, weld damage, holes, leakage and natural calamity. The application of robots for the maintenance of the pipe line utilities offers an efficient and economical approach to cater the problem. These pipe inspection robots are usually deployed in straight pipes, bend pipes, branch and stepped pipes of the chemical plant, power plant, waste water industry and underground urban gas sewages. Besides, these robots are employed in observation of wiring on high voltage power transmission towers \& cleaning of electric lights on lamp posts in a fixed duration. From the inclination of pipe inspection robot growth in recent years, development of IN-pipe robots are much faster than Out-pipe robot. But IN-pipe robots are not being functional during plant operation and faces constraints during variation of pipe configuration like elbow, step change, etc. These types of robot are applicable during installation of new pipelines or in plant shut down. Most of the robots have wheeled locomotion that gives wide acceptability but wheeled locomotion are not that much suitable for Out-pipe climbing robots which are dealing with pipes having higher diameter. There may be tendency of jamming during navigating on oxidized or ageing pipes also. Most suitable criteria are therefore to improvement with hybrid locomotion. Tracked wall-pressed type are better than wheeled wall-pressed type robots as they have more contact surface with the wall. Nevertheless, wheeled wall-pressed screw type robot has shown its advantages as per as the speed with ease is concerned. All the robots presented in the Table. 1 and are arranged chronologically and classified depending on their locomotion system.

Table 1. Classification of pipe-climbing robots according locomotion mechanism

\begin{tabular}{|c|c|c|c|c|c|c|c|c|c|}
\hline \multirow{3}{*}{ Sl. } & \multirow{3}{*}{ Name } & \multicolumn{7}{|c|}{ Locomotion System } & \multirow[b]{3}{*}{ Laboratory/Institute } \\
\hline & & \multirow{2}{*}{ 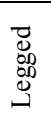 } & \multirow{2}{*}{ 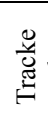 } & \multicolumn{3}{|c|}{ Wheeled } & \multicolumn{2}{|c|}{ Limbless } & \\
\hline & & & & $\ll む$ & $a \approx n$ & $I>$ & $\oplus$. & $\infty 0$ & \\
\hline 1 & TOSHIBA [27] & & & $x$ & & & & & Toshiba Corporation \\
\hline 2 & Robot [28] & & & & $x$ & & & & NEC Corporation \\
\hline 3 & THES-III [29] & & & & & $x$ & & & Tokyo Gas Co.Ltd \\
\hline 4 & Robot [13] & $x$ & & & & & & & Shanghai University \\
\hline 5 & HELI-PIPE [30] & & & & $x$ & & & & Universitelibre de bruxelles \\
\hline 6 & G-S platform [14] & $x$ & & & & & & & Technical University of madrid \\
\hline 7 & MORITZ [15] & $x$ & & & & & & & Technical University of Munich \\
\hline 8 & EXPLORER [59] & & & & & & $x$ & & Carnegie Mellon University \\
\hline 9 & MRINSPECT IV [1] & & & $x$ & & & & & Sungkyunkwan University, \\
\hline 10 & UT-PCR [31] & & & & & $x$ & & & University of Tehran \\
\hline 11 & Robot [32] & & & & & $x$ & & & ETH Zurich \\
\hline 12 & Robot [33] & & & & $x$ & & & & Shenyang Institute of Automation \\
\hline 13 & Robot [34] & & & & & $x$ & & & Swiss Federal Institute of Technology \\
\hline 14 & Robot [60] & & & & & & $x$ & & Shanghai University \\
\hline 15 & NTU-Navigator [35] & & & & & $x$ & & & National Taiwan University \\
\hline 16 & Robot [61] & & & & & & $x$ & & Korea Aerospace University \\
\hline 17 & Robot [62] & & & & & & & $x$ & Institute of Field Robotics, Thailand \\
\hline 18 & 3DCLIMBER [63] & & & & & & $x$ & & University of Coimbra \\
\hline 19 & RAUPI [64] & & & & & & $x$ & & Ilmenau University of Technology \\
\hline 20 & TUBULO [36] & & & $x$ & & & & & ETH Zurich \\
\hline 21 & FAMPER [18] & & $x$ & & & & & & Louisiana State University \\
\hline 22 & Robot [37] & & & & $x$ & & & & Ritsumeikan University \\
\hline 23 & Robot [38] & & & & $x$ & & & & BUPT Beijing \\
\hline 24 & Robot [65] & & & & & & & $x$ & Carnegie Mellon University \\
\hline 25 & Robot [39] & & & & & $x$ & & & Hanyang University \\
\hline 26 & Robot [66] & & & & & & & $x$ & Tohoku Gakuin University \\
\hline 27 & PAROYS-II [19] & & $x$ & & & & & & Yonsei University \\
\hline 28 & Robot [20] & & $x$ & & & & & & Kanagawa University \\
\hline 29 & Robot [40] & & & & & $x$ & & & Hanyang University, \\
\hline 30 & PIRATE [41] & & & $x$ & & & & & University of Twente \\
\hline 31 & Robot by [67] & & & & & & $x$ & & Yonsei University \\
\hline 32 & LS-01[21] & & $x$ & & & & & & Universiti Tenaga Nasional \\
\hline 33 & Robot [42] & & & $x$ & & & & & Yonsei University \\
\hline 34 & Robot [68] & & & & & & $x$ & & KAERI, Korea \\
\hline 35 & Robot [22] & & $x$ & & & & & & HanyangUniversity \\
\hline 36 & Robot [43] & & & $x$ & & & & & Universiti Tenaga Nasional \\
\hline 37 & Robot [23] & & $x$ & & & & & & Gunma University \\
\hline 38 & Robot [16] & $x$ & & & & & & & Sungkyunkwan University \\
\hline 39 & Robot [69] & & & & & & $x$ & & Indian Institute of Science \\
\hline 40 & Robot $[70]$ & & & & & & $x$ & & University of Toronto \\
\hline 41 & Spider-Like Robot [17] & $x$ & & & & & & & Corporate Research and Development, Munich \\
\hline
\end{tabular}

\section{Conclusion}

From discussion, it has been observed that several pipe climbing robots with several kinds of locomotion are proposed and tested. However, as the requirement changes, these types of locomotion provide some limitations for current situations. This review paper has discussed about the current development of pipe climbing robots, classified them 
based on their locomotion system and sorted them as a timeline. Researchers also have hybridized the particularly IN-pipe robot locomotion systems for a better performance. The experiments revealed that by applying hybrid system these robots can overcome the motion singularity problem especially when steering or navigating. Locomotion has been developed which are biologically inspired, provides more flexibility.

This is an Open Access article distributed under the terms of the Creative Commons Attribution Licence

\section{References}

1. Roh, S. G. and Choi, H. R., "Differential-Drive In-Pipe Robot for Moving Inside Urban Gas Pipelines," IEEE Transactions on Robotics, Vol. 21, No. 1, pp. 1-17, 2005.

2. Kim, Y. J., Yoon, K. H. and Park, Y. W., "Development of the Inpipe Robot for Various Sizes," Advanced Intelligent Mechatronics, pp. 1745-1749, 2009.

3. Ismail, I. N., Anuar, A., Sahari, K. S. M., Baharuddin, M. Z., Fairuz, M., Jalal, A. and Saad, J. M., "Development of in-pipe inspection robot: A review," Sustainable Utilization and Development in Engineering and Technology (STUDENT), pp. 310-315, 2012.

4. Archila, J. F. and Becker M., "Study of Robots to Pipelines, Mathematical Models and Simulation," Robotics Symposium and Competition (LARS/LARC), pp. 18-23, 2013.

5. Han, M., Zhou, J., Chen X. and Li, L., "Analysis of In-Pipe Inspection Robot Structure Design," 2nd Workshop on Advanced Research and Technology in Industry Applications (WARTIA), pp. 989-993, 2016.

6. Tatar, O. and Mandru, D., "Robotic Systems for Inspection and Exploration," ANNALS of the ORADEA UNIVERSITY. Fascicle of Management and Technological Engineering, Vol. VII (XVII), pp. 1112-1117, 2008.

7. Chu, B., Jung, K., Han, C. S. and Hong, D., "A Survey of Climbing Robots: Locomotion and Adhesion," International Journal of Precision Engineering and Manufacturing, Vol. 11, No. 4, pp. 633-647, 2010.

8. Kondoh, Y. and Yokota, S., "Micro In-Pipe Mobile Machines by Making Use of an Electro-Rheological Fluid," Proc. of the 1997 IEEE/RSJ International Conference on Intelligent Robots and Systems, Vol. 3, pp. 1672-1677, 1997.

9. Sun, L., Sun, P., Qin, X. and Wang, C., "Micro Robot in Small Pipe with Electromagnetic Actuator," Proc. of the 1998 International Symposium on Micromechatronics and Human Science, pp. 243-248, 1998.

10. Sakamoto, S., Hara, F., Hosokai, H., Kinoshita, H. and Abe, Y., "Parallel-Link Robot for Pipe Inspection," Proc. of the 2005 IEEE 31st Annual Conference on Industrial Electronics Society, pp. 345-350, 2005.

11. Ariga, A., Kobayashi T., Yamaguchi, T. and Hashimoto, S., "Wall climbing robot in narrow space with pantograph-type structure," Proc. of the 2010 IEEE International Conference on Robotics and Biomimetics (ROBIO), pp. 1507-1512, 2010.

12. Yamamoto, T., Konyo, M. and Tadokoro, S., "A High-speed Locomotion Mechanism Using Pneumatic Hollow-shaft Actuators for In-pipe Robots," Proc. of the 2015 IEEE/RSJ International Conference on Intelligent Robots and Systems (IROS), pp. 4724-4730, 2015.

13. Sun, L., Zhang, Y., Sun, P. and Gong, Z., "Study on Robots with PZT Actuator for small pipe," Proc. of the 2001 International Symposium on Micromechatronics and Human Science, pp. 149-154, 2001.

14. Aracil, R., Saltaren, R. and Reinoso, O., "Parallel robots for autonomous climbing along tubular structures," Robotics and Autonomous Systems, Vol. 42, No. 2, pp. 125-134, 2003.

15. Zagler, A. and Pfeiffer, F., "MORITZ a pipe crawler for tube junctions," Proc. of the 2003 IEEE International Conference on Robotics \& Automation (ICRA), Vol. 3, pp. 2954-2959, 2003.

16. Han, S. C., An, J. and Moon, J., "A Remotely Controlled Out-Pipe Climbing Robot," Proc. of the 10th International Conference on Ubiquitous Robots and Ambient Intelligence (URAI), pp. 126, 2013.

17. Neubauer, W., "A Spider-Like Robot that Climbs Vertically in Ducts or Pipes," Proc. of the 1994 IEEE/RSJ/GI International Conference on Intelligent Robots and Systems (IROS), Vol. 2, pp.
1178-1185, 1994.

18. Kim, J. H., Sharma, G. and Iyengar, S. S., "FAMPER: A Fully Autonomous Mobile Robot for Pipeline Exploration," Proc. of the 2010 IEEE International Conference on Industrial Technology (ICIT), pp. 517-523, 2010

19. Park, J., Hyun, D., Cho, W. H., Kim, T. H. and Yang, H. S., " Normal-Force Control for an In-Pipe Robot According to the Inclination of Pipelines," IEEE Transactions on Industrial Electronics, Vol. 58, No. 12, pp. 5304-5310, 2011.

20. Sato, K., Ohki, T. and Lim, H. O., "Development of In-Pipe Robot Capable of Coping with Various Diameters," Proc. of the 11th International Conference on Control Automation and Systems (ICCAS), pp. 1076-1081, 2011.

21. Baharuddin, M. Z., Saad, J. M., Anuar, A., Ismail, I. N., Basri, N. M. H., Roslin, N. S., Mohideen, S. S. K., Jalal, M. F. A. and Salleh, K., "Robot for Boiler Header Inspection "LS-01"," International Symposium on Robotics and Intelligent Sensors (IRIS), Vol. 41, pp. 1483-1489, 2012.

22. Kwon, Y. S. and Yi, B. J., "Design and Motion Planning of a Two-Module Collaborative Indoor Pipeline Inspection Robot," IEEE Transactions on Robotics, Vol. 28, No. 3, pp. 681-696, 2012.

23. Nagaya, K., Yoshino, T., Katayama, M., Murakami, I. and Ando, Y., "Wireless Piping Inspection Vehicle Using Magnetic Adsorption Force," IEEE/ASME Transactions on Mechatronics, Vol. 17, No. 3, pp. 472-479, 2012.

24. Kim, D. W., Park, C. H., Kim, H. K.and Kim, S. B., "Force Adjustment of an Active Pipe Inspection Robot," Proc. of the 2009 International Joint Conference (ICROS-SICE), pp. 3792-3797, 2009.

25. Nagase, J. Y. and Fukunaga, F., "Development of a novel crawler mechanism for pipe inspection," Proc. of the 42nd Annual Conference of the IEEE Industrial Electronics Society (IECON), pp. 5873-5878, 2016.

26. Kakogawa, A. and Ma, S., "Speed analysis for three driving modules of an in-pipe inspection robots for passing through bent pipes," Proc. of the 2014 IEEE International Conference on Robotics and Biomimetics (ROBIO), pp. 1731-1736, 2014.

27. Roh, S. G. and Choi, H. R., "Differential-drive in-pipe robot for moving inside urban gas pipelines," IEEE Transactions on Robotics, Vol. 21, No. 1, pp. 1-17, 2005.

28. Yamaguchi, T., Kagawa, Y., Hayashi, I., Iwatsuki, N., Morikawa, K. and Nakamura, K., "Screw principle microrobot passing steps in a small pipe," Proc. of the International Symposium on Micromechatronics and Human Science, pp. 149-152, 1999.

29. Hirose, S., Ohno, H.,Mitsui, T. and Suyama, K., "Design of in-pipe inspection vehicles for $\varphi 25, \varphi 50, \varphi 150$ pipes," Proc. of the 1999 IEEE International Conference on Robotics and Automation, Vol. 3, pp. 2309-2314, 1999.

30. Horodinca, M., Doroftei, I., Mignon, E. and Preumont, A., "A simple architecture for in-pipe inspection robots," in International Colloquium on Mobile and Autonomous Systems, pp. 1-4, 2002.

31. Baghani, A., Ahmadabadi, M. N. and Harati, A., "Kinematics Modeling of a Wheel-Based Pole Climbing Robot (UT-PCR)" Proc. of the 2005 IEEE International Conference on Robotics and Automation, pp. 2099-2104, 2005.

32. Tache, F.,Fischer, W., Siegwart, R., Moser, R. and Mondada. F., "Compact magnetic wheeled robot with high mobility for inspecting complex shaped pipe structures," Proc. of the 2007 IEEE/RSJ International Conference on Intelligent Robots and Systems (IROS), pp. 261-266, 2007.

33. Li, P., Ma, S., Li, B. and Wang, Y., "Development of an Adaptive Mobile Robot for In-Pipe Inspection Task," Proc. of the 2007 International Conference on Mechatronics and Automation, pp. 3622-3627, 2007. 
34. Fischer, W., Tache, F. and Siegwart, R., "Magnetic Wall Climbing Robot for Thin Surfaces with Specific Obstacles," published in 6th International Conference on Field and Service Robotics, pp. 551-561, 2008.

35. Lu, C. P., Huang, H. P., Yan, J. L. and Cheng, T. H., "Development of Pipe Inspection Robot," Proc. of the 33rd Annual Conference of the IEEE Industrial Electronics Society, pp. 626-631, 2007.

36. Schoeneich, P., Rochat, F., Nguyen, O. T. D., Caprari, G., Moser, R., Bleuler, H. and Mondada, F., "Tubulo - a train-like miniature inspection climbing robot for ferromagnetic tubes," Proc. of the 1st International Conference on Applied Robotics for the Power Industry (CARPI), pp. 1-5, 2010.

37. Kakogawa, A. and Ma, S., "Mobility of an In-pipe Robot with Screw Drive Mechanism inside Curved Pipes," Proc. of the 2010 IEEE International Conference on Robotics and Biomimetics, pp. 1530-1535, 2010.

38. Yanheng, Z., Mingwei, Z., Hanxu, S. and Qingxuan, J., "Design and Motion Analysis of a Flexible Squirm Pipe Robot," Proc. of the 2010 International Conference on Intelligent System Design and Engineering Application (ISDEA), Vol. 1, pp. 527-531, 2010.

39. Kwon, Y. S., Lee, B., Whang, I. C. and Yi, B. J., "A Pipeline Inspection Robot with a Linkage Type Mechanical Clutch," Proc. of the 2010 IEEE/RSJ International Conference on Intelligent Robots and Systems (IROS), pp. 2850-2855, 2010.

40. Kwon, Y. S., Lee, B., Whang, I. C., Kim, W. K. and Yi, B.J., “A Flat Pipeline Inspection Robot with Two Wheel Chains," Proc. of the 2011 IEEE International Conference on Robotics and Automation, pp. 5141-5146, 2011.

41. Dertien, E., Foumashi, M. M., Pulles, K., Stramigioli, S. and Zwicker, E., "Development of an inspection robot for small diameter distribution mains," Proc. of the 2011 IEEE International Conference on Robotics and Automation (ICRA), pp. 5044-5049, 2011.

42. Lee, D., Park, J., Hyun, D., Yook, G. and Yang, H. S., "Novel mechanisms and simple locomotion strategies for an in-pipe robot that can inspect various pipe types," Mechanism and Machine Theory, Vol. 56, pp. 52-68, 2012.

43. Zin, M. R. A. M., Sahari, K. S. M., Saad, J. M.,Anuar, A. and Zulkarnain, A. T., "Development of a Low Cost Small Sized In-Pipe Robot," International Symposium on Robotics and Intelligent Sensors (IRIS), vol. 41, pp. 1469-1475, 2012.

44. Zhang, Y. and Yan, G., "In-pipe inspection robot with active pipe-diameter adaptability and automatic tractive force adjusting," Mechanism and Machine Theory, Vol. 42, pp. 1618-1631, 2007.

45. Nayak, A. and Pradhan, S. K., "Design of a New In-Pipe Inspection Robot," 12th Global Congress on Manufacturing and Management (GCMM), Vol. 97, pp. 2081-2091, 2014.

46. Roh, S. G., Ryew, S.M., Yang, J.H. and Choi, H. R., "Actively Steerable Inpipe Inspection Robots for Underground Urban Gas Pipelines,"Proc. of the 2001 IEEE International Conference on Robotics and Automation, Vol. 1, pp. 761-766, 2001.

47. Kimura, H. and Hirose S., "Development of Genbu Active wheel passive joint articulated mobile robot," Proc. of the IEEE/RSJ International Conference on Intelligent Robots and Systems, Vol. 1, pp. 823-828, 2002.

48. Kamegawa, T., Harada, T. and Gofuku, A., "Realization of cylinder climbing locomotion with helical form by a snake robot with passive wheels," Proc. of the 2009 IEEE International Conference on Robotics and Automation, pp. 3067-3072, 2009.

49. Lim, H. O. and Ohki, T., "Development of Pipe Inspection Robot," Proc. of the 2009 International Joint Conference ICROS-SICE, pp. 5717-5721, 2009.

50. Tatar, M. O., Cireba, C. and Mandru, D., "The Development of an In-Pipe Mini robot for Various Pipe Sizes," Proc. of the 2012 IEEE International Conference on Automation Quality and Testing Robotics (AQTR), pp. 443-448, 2012.

51. Nishimura, T., Kakogawa, A. and Ma, S., "Pathway Selection Mechanism of a Screw Drive In-pipe Robot in T-branches," Proc. of the 2012 IEEE International Conference on Automation Science and Engineering (CASE), pp. 612-617, 2012.

52. Sibai, F. N., Sayegh, A. and Al-Taie, I., "Design And Construction of An In-pipe Robot for Inspection and Maintenance," Proc. of the 2012 International Conference on Computer Systems and Industrial Informatics (ICCSII), pp. 1-6, 2012.

53. Li, T., Ma, S., Li, B., Wang, M. and Wang, Y., "Design of Spring Parameters for a Screw Drive In-Pipe Robot Based on Energy Consumption Model," Proc. of the 2014 11th World Congress on Intelligent Control and Automation (WCICA), pp. 3292-3297,
2014.

54. Hiraoka, N., Tatsuno, J. and Inagaki, K., "Omnidirectional Motion Planning for a Leg-wheeled Robot with Reduced DOF and Using Passive Wheels," Proc. of the 2016 14th International Conference on Control, Automation, Robotics and Vision (ICARCV), pp. 1-6, 2016.

55. Tourajizadeh, H. and Rezaei, M., "Design and Control of a Steerable Screw In-pipe Inspection Robot,” Proc. of the 2016 4th International Conference on Robotics and Mechatronics (ICROM), pp. 98-104, 2016.

56. Song, H., Ge, K., Qu, D., Wu, H. and Yang, J., "Design of in-pipe robot based on inertial positioning and visual detection," Advances in Mechanical Engineering, Vol. 8, No. 9, pp. 1-22, 2016.

57. Huang, K., Shao, K., Zhen, S. and Sun, H., "A novel approach for modeling and tracking control of a passive-wheel snake robot," Advances in Mechanical Engineering, Vol. 9, No. 3, pp. 1-15, 2017.

58. Suzuki, M., Yukawa, T., Satoh, Y. and Okano, H., "Mechanisms of Autonomous Pipe-Surface Inspection Robot with Magnetic Elements," Proc. of the 2006 IEEE International Conference on Systems, Man and Cybernetics, Vol. 4, pp. 3286-3291, 2006.

59. Schempf, H.,Mutschler, E., Goltsberg, V., Skoptsov, G., Gavaert, A. and Vradis, G., "Explorer: Untethered real-time gas main assessment robot system," Proc. of the 1st International Workshop on Advances in Service Robotics (ASER'03), 2003.

60. Li, C. and He, X., "A Bio-Mimetic Pipe Crawling Micro robot Driven Based on Self-Excited Vibration," Proc. of the 2007 IEEE International Conference on Robotics and Biomimetics, pp. 984-988, 2007.

61. Lim, J., Park, H., Moon, S. and Kim, B., "Pneumatic Robot Based on Inchworm Motion for Small Diameter Pipe Inspection," Proc. of the 2007 IEEE International Conference on Robotics and Biomimetics, pp. 330-335, 2007.

62. Maneewarn, T. and Maneechai, B., "Design of Pipe Crawling Gaits for a Snake Robot," Proc. of the 2008 IEEE International Conference on Robotics and Biomimetics (ROBIO), pp. 1-6, 2009.

63. Tavakoli, M., Marjovi, A., Marques, L. and T.de Almeida, A., "3DCLIMBER: A climbing robot for inspection of 3D human made structures," proc. of the 2008 IEEE/RSJ International Conference on Intelligent Robots and Systems, pp. 4130-4135, 2008.

64. Mampel, J., Gerlach, K., Schilling, C. and Witte, H., "A modular robot climbing on pipe-like structures," Proc. of the 4th International Conference on Autonomous Robots and Agents, pp. 87-91, 2009.

65. Degani, A., Feng, S., Choset, H. and T. Mason, M., "Minimalistic, Dynamic, Tube Climbing Robot," Proc. of the 2010 IEEE International Conference on Robotics and Automation (ICRA), pp. 1100-1101, 2010.

66. Yaguchi, H., Sato, N. and Shikoda, A., "Magnetic Actuator Group of Globular Type Capable of Free Movement in a Complex Pipe,'IEEE Transactions on Magnetics, Vol. 47, No. 10, pp. 4159-4162, 2011.

67. Jeon, W., Park, J., Kim, I., Kang, Y. K. and Yang, H., "Development of high mobility in-pipe inspection robot," Proc. of the 2011 IEEE/SICE International Symposium on System Integration (SII), pp. 479-484, 2011.

68. Kim, J. H., Lee, J. C. and Choi, Y. R., "Vision based Pole Climbing Robot," Proc. of the 2012 International Symposium on Optomechatronic Technologies (ISOT), pp. 1-2, 2012.

69. Singh, P. and Ananthasuresh, G. K., "A Compact and Compliant External Pipe-Crawling Robot," IEEE Transactions on Robotics, Vol. 29, No. 1, pp. 251-260, 2013.

70. Qiao, J., Shang, J. and Goldenberg, A., "Development of Inchworm In-Pipe Robot Based on Self-Locking Mechanism," IEEE/ASME Transactions on Mechatronics, Vol. 18, No. 2, pp. 799-806, 2013.

71. Dowling, K., "Limbless locomotion: learning to crawl," Proc. of the 1999 IEEE International Conference on Robotics and Automation, Vol. 4, pp. 3001-3006, 1999.

72. Wakimoto, S., Nakajima, J., Takata M., Kanda, T. and Suzumori, K., "A Micro Snake-like Robot for Small Pipe Inspection," Proc. of the 2003 International Symposium on Micromechatronics and Human Science (MHS), pp. 303-308, 2003.

73. Chen, L., Wang, Y., Ma, S. and Li, B., "Analysis of Traveling Wave Locomotion of Snake Robot," Proc. of the 2003 IEEE International Conference on Robotics Intelligent Systems and Signal Processing, Vol. 1, pp. 365-369, 2003. 
74. Qi, T., Kamegawa, T. and Gofuku, A., "Proposal of helical wave propagate motion for a snake robot to across a branch on a pipe," Proc. of the 2016 IEEE/SICE International Symposium on System Integration (SII), pp. 821-826, 2016.

75. Das, M., Agrawal, A., Sonone, A., Gupta, R., Upadhyay, D., Rao, Y. and Javed, A., "Developing a Bioinspired Pole Climbing Robot,"Proc. of the 2016 International Conference on Robotics: Current Trends and Future Challenges (RCTFC), pp. 1-6, 2016

76. Trebuna, F., Virgala, I., Pastor, M., Liptak, T. and Mikova, L., "An inspection of pipe by snake robot," International Journal of Advanced Robotic Systems, pp. 1-12, 2016.

77. Yamazaki, S., Tanise, Y., Yamada, Y. and Nakamura, T. "Development of axial extension actuator for narrow pipe inspection endoscopic robot," Proc. of the 2016 IEEE/SICE International Symposium on System Integration, Proc. of the 2016 IEEE/SICE International Symposium on System Integration (SII), pp. 634-639, 2016.

78. Lim, J., Park, H., An, J., Hong, Y. S., Kim, B. and Yi, B. J., "One pneumatic line based inchworm-like micro robot for half-inch pipe inspection," 8th International IFAC Symposium on Robot Control,
Vol. 18, No. 7, pp. 315-322, 2008.

79. Yang, J., Xue, Y., Shang, J. and Luo, Z., "Research on a New Bilateral Self-locking Mechanism for an Inchworm Micro In-pipe Robot with Large Traction," International Journal of Advanced Robotic Systems, pp. 1-11, 2014.

80. Yoon, K. H. and Park, Y. W., "Pipe Inspection Robot Actuated by Using Compressed Air," Proc. of the 2010 IEEE/ASME International Conference on Advanced Intelligent Mechatronics, pp. 1345-1349, 2010.

81. Liu, Q., Chen, Y., Ren, T. and Wei, Y., "Optimized inchworm motion planning for a novel in-pipe robot," Journal of Mechanical Engineering Science, Vol. 228, No. 7, pp. 1248-1258, 2014.

82. Choi, C., Park, B. and Jung, S., "The Design and Analysis of a Feeder Pipe Inspection Robot With an Automatic Pipe Tracking System," IEEE/ASME Transactions on Mechatronics, Vol. 15, No. 5, PP. 736-745, 2010.

83. Schmidt, D. and Berns, K., "Climbing robots for maintenance and inspections of vertical structures-A survey of design aspects and technologies," Robotics and Autonomous Systems, Vol. 61, No. 12, PP. 1288-1305, 2013. 